\title{
Decreased Hemojuvelin Protein Levels in Mask Mice Lacking Matriptase-2-Dependent Proteolytic Activity
}

\author{
J. FRÝDLOVÁ ${ }^{1}$, Y. FUJIKURA ${ }^{1}$, M. VOKURKA ${ }^{1}$, E. NEČAS ${ }^{1}$, J. KRIJT ${ }^{1}$ \\ ${ }^{1}$ Institute of Pathophysiology, First Faculty of Medicine, Charles University, Prague, Czech \\ Republic
}

Received August 27, 2012

Accepted January 25, 2013

On-line April 16, 2013

\begin{abstract}
Summary
Matriptase-2, a membrane protein encoded by the Tmprss6 gene, is a negative regulator of hepcidin expression. Although matriptase-2 has been proposed to cleave membrane hemojuvelin, we have recently found decreased hemojuvelin protein levels in Tmprss 6 -/- mice. The purpose of this study was to confirm this observation by determining hemojuvelin protein levels in another strain of mice with disrupted Tmprss 6 gene, and to determine the effect of matriptase- 2 deficiency on the expression of other membrane proteins participating in the bone morphogenetic protein signal transduction. Mask mice, which lack the proteolytic domain of matriptase-2, displayed decreased liver hemojuvelin protein content, while Id1 mRNA level, an indicator of hemojuvelin-dependent signal transduction, was increased. Protein levels of bone morphogenetic protein receptors Alk3 and Acvr2a were unchanged, and transferrin receptor 2 and neogenin protein levels were slightly decreased. The results confirm that the loss of matriptase- 2 increases bone morphogenetic proteindependent signaling, while paradoxically decreasing liver hemojuvelin protein content. The regulation of transferrin receptor 2 protein levels by transferrin saturation was not affected in mask mice. How the loss of matriptase-2 proteolytic activity leads to decreased hemojuvelin protein levels is at present unclear.
\end{abstract}

\section{Key words}

Hepcidin • Id1 • Tmprss6 - Hfe2 - Transferrin receptor 2 • Neogenin

\section{Corresponding author}

J. Krijt, Institute of Pathophysiology, First Faculty of Medicine, Charles University, U Nemocnice 5, 12853 Prague 2, Czech Republic. E-mail: jkri@lf1.cuni.cz

\section{Introduction}

Iron-deficiency anemia is the most common anemia worldwide. Although the overwhelming majority of iron-deficiency anemia cases are caused by chronic bleeding or inadequate dietary iron intake, a minor subgroup of iron-deficiency anemias is inherited in an autosomal recessive manner. Recently, it has been demonstrated that rare cases of iron-refractory iron deficiency anemia (IRIDA) are caused by mutations of the TMPRSS6 gene (Finberg et al. 2008).

The exact function of the TMPRSS6 gene is at present unknown. The gene encodes a serine protease, matriptase-2, which is expressed mainly at the hepatocyte plasma membrane. In vitro, matriptase- 2 has been convincingly demonstrated to cleave hemojuvelin (Silvestri et al. 2008), another hepatocyte plasma membrane protein, which plays an essential role in the regulation of expression of hepcidin, the key ironregulatory hormone. Hemojuvelin (Hjv) is a central component of the bone morphogenetic protein /hemojuvelin (Bmp/Hjv) signaling pathway, which upregulates hepcidin expression in response to increased iron stores (Babitt et al. 2006). In this pathway, hemojuvelin facilitates the binding of the Bmp6 protein (Andriopoulos et al. 2009, Meynard et al. 2009) to a set of bone morphogenetic protein receptors at the extracellular side of the hepatocyte plasma membrane, leading to intracellular receptor phosphorylation, phosphorylation of the Smad1/5/8 proteins and, ultimately, to transcriptional activation of hepcidin expression. By cleaving plasma membrane hemojuvelin, matriptase-2 is thus proposed to remove an important 
component of the Bmp/hemojuvelin pathway from the membrane, resulting in diminished hepcidin expression. In accordance with this concept, lack of matriptase-2, as in IRIDA patients, leads to inappropriate high expression of hepcidin (Finberg et al. 2008), which causes a decrease in iron absorption from the intestine.

At present, three well-characterised mouse models of matriptase-2 deficiency exist: mask mice on C57BL/6 background, which harbor an ethylnitrosoureainduced mutation a splice acceptor site upstream of exon 15 of the Tmprss 6 gene, resulting in the loss of the proteolytic domain of matriptase-2 (Du et al. 2008); Tmprss6-/- mice on a mixed background, in which the expression of matriptase-2 was compromised by duplication of exons 3 to 6 (Folgueras et al. 2008), and finally Tmprss 6 mutant mice on a C57BL/6 background, obtained by deletion of a part of exon 17 , again resulting in the loss of a part of the protease domain of matriptase-2 (Finberg et al. 2010). The phenotype of these strains is very similar, with truncal alopecia and iron-deficiency anemia as most prominent findings. All three strains display elevated expression of hepcidin, which is in accordance with enhanced signaling through the $\mathrm{Bmp} / \mathrm{Hjv}$ pathway. Despite these similarities, there are also slight differences between the phenotypes of the mutant strains, particularly with respect to the survival of offspring (Folgueras et al. 2008, Finberg et al. 2010) or expression of the Bmp6 gene (Finberg et al. 2008, Nai et al. 2012).

When recently investigating Hjv protein levels in Tmprss6-/- (Folgueras et al. 2008) mice, we surprisingly found decreased, rather than increased, levels of hemojuvelin protein (Krijt et al. 2011). This observation suggests that, in vivo, the actual function of matriptase- 2 in iron metabolism regulation could be more complex than simple cleavage of plasma membrane hemojuvelin. The purpose of the present investigation was to confirm this observation by examining hemojuvelin protein levels in mask mice, and to determine the effect of matriptase- 2 deficiency on the expression of other proteins participating in the bone morphogenetic protein signal transduction.

\section{Methods}

Animal experiments were approved by the Ethics Committee of the First Faculty of Medicine in Prague.

Liver samples from male mask mice, aged three to four months (Du et al. 2008), were processed to obtain either whole tissue homogenate or crude membrane fraction. For whole tissue homogenates, liver samples were homogenised in $150 \mathrm{mM}$ sodium chloride, $\mathrm{pH} 7.8$, containing protease inhibitors (Roche) and $1 \%$ of Triton $\mathrm{X}-100$. Homogenate was centrifuged for $15 \mathrm{~min}$ at $12000 \mathrm{~g}$, and $60 \mu \mathrm{g}$ of the supernatant protein was used for electrophoresis. Crude membrane fraction was obtained by homogenisation of liver samples in $250 \mathrm{mM}$ sucrose, pH 7.5, containing protease inhibitors. After low-speed centrifugation at $6000 \mathrm{~g}$ for $15 \mathrm{~min}$, the crude membrane fraction was isolated by ultracentrifugation of the homogenate at $80000 \mathrm{~g}$ for $50 \mathrm{~min}$. The pellet was resuspended in Tris-buffered saline, $\mathrm{pH} 7.5$, and a $60 \mu \mathrm{g}$ protein aliquot was used for electrophoresis on $12 \%$ polyacrylamide gels. For neogenin determinations, $6 \%$ polyacrylamide gel was utilized. A total of four pairs of C57BL/6 and mask mouse livers, originating from agematched mice kept on a standard laboratory diet, were used for the experiments.

Immunoblotting was performed on an Invitrogen semi-dry blotter, PVDF membrane was blocked for one hour in $5 \%$ milk in tris-buffered saline containing $0.1 \%$ Tween 20, and incubated overnight with the primary antibody in $5 \%$ milk. The primary antibodies were: Goat anti-Hjv, AF 3634, R\&D Systems, 1:500; rabbit antitransferrin receptor 2 (Tfr2), Alpha Diagnostics International, 1:1000; rabbit anti-Acvr1 (Alk2), \#4398, Cell Signaling Technology, 1:250; rabbit anti-Bmpr1a (Alk3), ab59947, Abcam, 1:300; rabbit anti-Actr-IIa (Acvr2a), sc-130679, Santa Cruz Biotechnology, 1:200, and rabbit anti neogenin (Neo1), sc-15337, Santa Cruz Biotechnology, 1:500. Rabbit anti pan-cadherin, \#4068, Cell Signaling Technology, 1:24 000, and rabbit antiGapdh, G9545, Sigma Aldrich, 1:250 000, were used as loading controls. Secondary antibodies were from Jackson ImmunoResearch.

RNA was isolated from samples stored at $-80^{\circ} \mathrm{C}$ using Qiagen RNeasy Plus Mini Kit, and reverse transcribed by RevertAid First Strand cDNA synthesis kit (Thermo Scientific). Real-time PCR was performed on a Roche Light Cycler instrument as previously described (Krijt et al. 2011), target mRNA content is expressed relative to $\beta$-actin (Actb) mRNA. Primer sequences were (forward and reverse): Actb GAC ATG GAG AAG ATC TGG CA and GGT CTT TAC GGA TGT CAA CG, Acvrl AGG TTT ATG AGC AGG GGA AGA and CTG AGA GCA ACT CCA AGG ATG, Bmprl TCG AGA CCT GAA GAG CAA AAA and GAT GTA GGG CTG 
GAA ATG GTT, Hfe2 CAA TCC TGC GTC TTT GAT GTT and GAA GCA AAG CCA CAG AAC AAA, IdI CGA GGT GGT ACT TGG TCT GTC and CTG CAG GTC CCT GAT GTA GTC, Neol CTT GAT GCC AGC AAC TGT GTA and ATT TCC CCA TTG CCA GAT AAC.

\section{Results}

Hjv protein is decreased in mask mice

As previously reported (Krijt et al. 2011), the R\&D AF3634 antibody detects, under reducing conditions, two Hjv-specific bands in vivo - a major band at approximately $35 \mathrm{kDa}$, and a minor band at approximately $18 \mathrm{kDa}$. Comparison of whole liver homogenates from mask mice and their wild-type littermates showed significant downregulation of the major $35 \mathrm{kDa}$ band (Fig. 1A); the minor band was barely visible. When the same samples were run under nonreducing conditions, only one band at approximately $50 \mathrm{kDa}$, probably representing a disulfide bridge-bound Hjv heterodimer (Zhang et al. 2005), was apparent. The intensity of this band was decreased in mask mice (Fig. 1B).

To enhance the visualisation of the $35 \mathrm{kDa}$ band, crude liver membrane fraction was prepared by ultracentrifugation. Hjv signal from the crude membrane fraction was stronger as compared to the whole homogenate; the intensity of both the 35 and $18 \mathrm{kDa}$ bands (Fig. 1C, reducing conditions), as well as the single $50 \mathrm{kDa}$ band (Fig. 1D, non-reducing conditions), reproducibly decreased in mask mice. These results confirm that the disruption of Tmprss 6 gene significantly decreases hemojuvelin protein content.

Matriptase-2 does not decrease membrane Tfr2, Alk3, Acvr2a and neogenin protein content

Since matriptase- 2 is a hepatocyte membrane protein, it was of interest to determine whether disruption of the Tmprss6 gene will affect the content of other membrane proteins participating in iron homeostasis. Of these, transferrin receptor 2 ( $(\mathrm{fr} 2$ ) is of particular interest, since it is also selectively expressed in the hepatocyte (Fleming et al. 2000), and therefore represents a potential target for matriptase- 2 activity. As can be seen in Figure $3 \mathrm{~A}$, the levels of transferrin receptor 2 slightly decreased in mask mice, as compared to wild-type littermates. To confirm that the antibody indeed allows reliable detection of Tfr2 protein, we determined Tfr2 protein levels in two female C57BL/6 mice fed an iron-deficient diet (Altromin C 1038, iron content $10 \mathrm{mg} / \mathrm{kg}$ ) for three weeks since weaning, as well as in two three months old female $\mathrm{C} 57 \mathrm{BL} / 6$ mice treated with a single intraperitoneal dose of iron dextran (200 $\mathrm{mg}$ iron $/ \mathrm{kg})$. In addition, we also determined $\mathrm{Tfr} 2$ protein in two male $\mathrm{Hjv}$-/- mice. In all cases, Tfr2 protein levels reacted to the changes in body iron levels (Fig. 2), which is in accordance with published data (Johnson and Enns 2004).
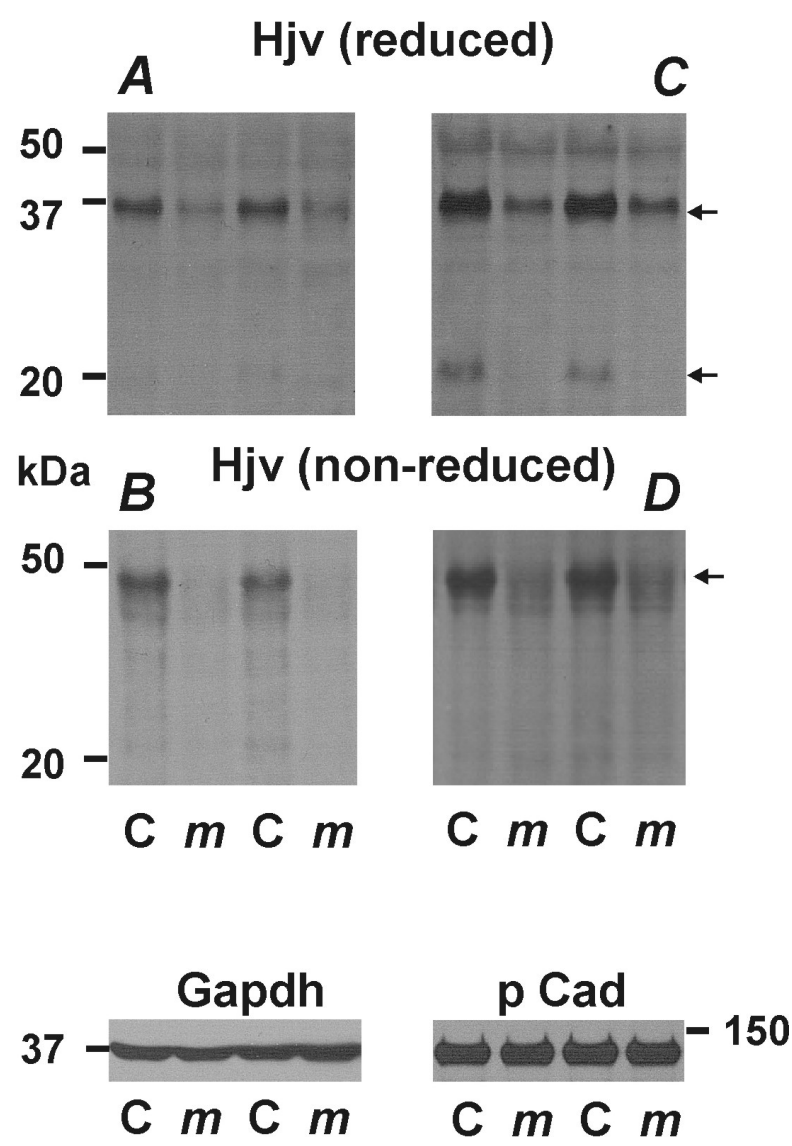

Fig. 1. Liver hemojuvelin protein levels in mask mice. A and B: Liver Hjv protein levels determined in whole tissue homogenate, under reducing and non-reducing conditions respectively. $\mathbf{C}$ and D: Liver Hjv protein levels determined in crude membrane fraction, under reducing and non-reducing conditions respectively. C: male C57BL/6 mice, $m$ : age-matched mask mice. Gapdh and pan-cadherin were used as loading controls. $60 \mu \mathrm{g}$ of protein was loaded per lane.

The signal from bone morphogenetic proteins is transduced by bone morphogenetic protein receptors. Bmp6 has been reported to interact with Alk2 and Alk3, both type 1 Bmp receptors (Steinbicker et al. 2011), which are presumed to interact with type 2 Bmp receptors (Xia et al. 2008). Of the type 2 receptors, Acvr2a has been reported as the most abundant in human liver (Xia et al. 2008). Using commercially available antibodies, we 
Tfr2

kDa
100
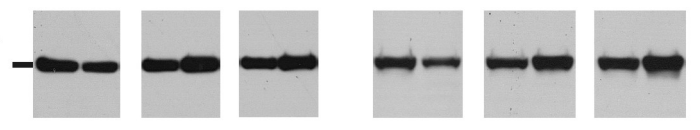

p Cad

150
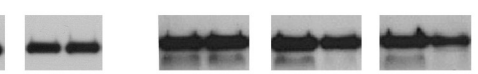

C Id C Fe WTKO C Id C Fe WT KO

Fig. 2. Response of liver Tfr2 protein to iron deficiency and iron overload. Female C57BL/6 mice were kept on iron-deficient diet since weaning for three weeks (Id), or were injected with $200 \mathrm{mg} / \mathrm{kg}$ iron and sacrificed after three days (Fe). Male $\mathrm{Hjv}+/+$ (WT) and $H j v-/-(K O)$ mice were sacrificed at 5 months. Liver iron content in the respective groups was: Control (C), $80 \mu \mathrm{g} / \mathrm{g}$; Id, $20 \mu \mathrm{g} / \mathrm{g} ; \mathrm{Fe}, 1730 \mu \mathrm{g} / \mathrm{g} ; \mathrm{WT}, 40 \mu \mathrm{g} / \mathrm{g}$ and $\mathrm{KO}, 1390 \mu \mathrm{g} / \mathrm{g}$ (wet weight). $60 \mu \mathrm{g}$ of crude membrane protein was loaded per lane, pan-cadherin was used as loading control.

detected protein bands corresponding to Alk3 and Acvr2a. The expression of these proteins was not significantly changed in mask mice (Fig. 3A). The Alk2 antibody produced only very weak bands at the expected band size of $60 \mathrm{kDa}$, although, as stated by the manufacturer, it showed strong bands of unknown origin at $95 \mathrm{kDa}$ (Fig. 3A).

Several groups have reported that iron metabolism is influenced by neogenin (Zhang et al. 2005, Lee et al. 2010). In liver crude membrane preparations from mask mice, we detected slightly decreased membrane neogenin protein levels (Fig. 3A). Overall, these results suggest that Alk3, Acvr2a and neogenin are not physiological substrates of matriptase-2.

\section{The decrease in Hjv protein occurs posttranscriptionally}

To verify that the observed changes in $\mathrm{Hjv}$ protein occur posttranscriptionally, levels of $\mathrm{Hfe} 2$ mRNA, coding the Hjv protein, were determined by realtime PCR. Hfe 2 mRNA content was unchanged in mask mice (Fig. 3B). In addition, no changes were observed in Acvr1, Bmprla and Neol mRNA, encoding the Alk2, Alk3 and neogenin proteins (results not shown).

Id1 mRNA levels in mask mice confirm upregulation of Bmp-dependent signal transduction, despite decreased Hjv protein levels

Liver Idl mRNA levels are often used to monitor Bmp6-dependent signaling. In iron-deficient C57BL mice, liver Id 1 mRNA levels are decreased in comparison with control mice (Kautz et al. 2008).
A
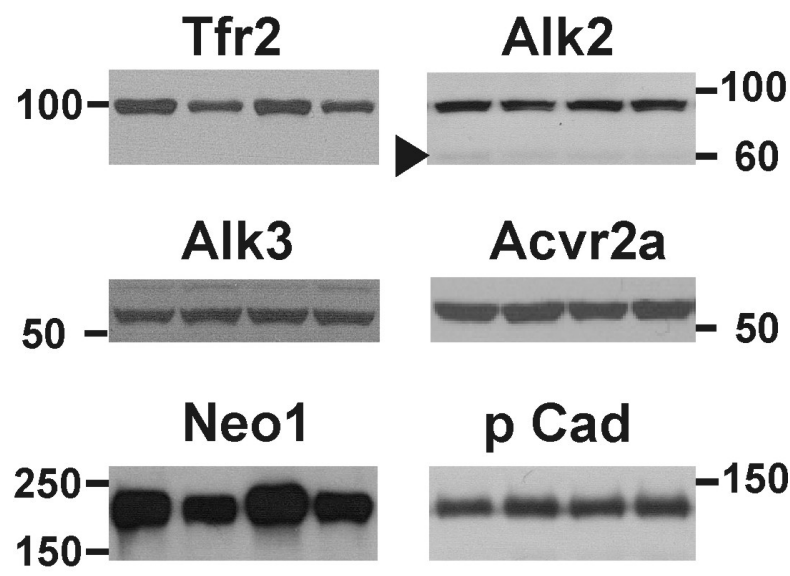

C $m \mathrm{C} \quad \mathrm{C} \mathrm{m} m$

B
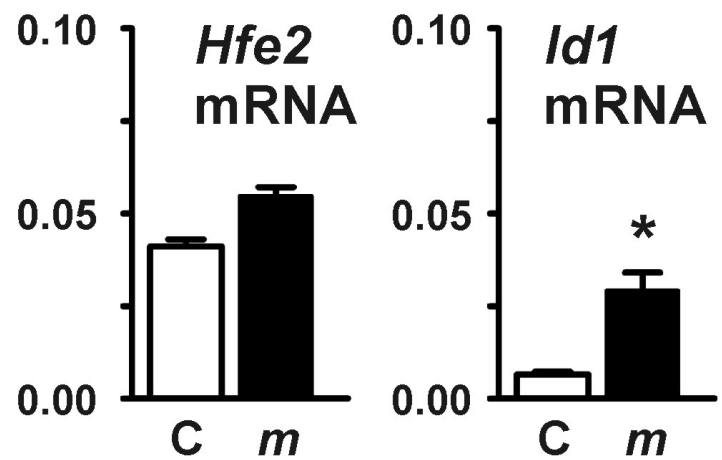

Fig. 3. Hemojuvelin-related proteins in the liver of mask mice. Panel A: Tfr2, Alk2, Alk3, Acvr2a and neogenin (Neo1) protein levels determined in crude membrane fraction under reducing conditions. C: C57BL/ 6 mice, m: mask mice. $60 \mu \mathrm{g}$ of protein was loaded per lane. Pan-cadherin is used as loading control. Arrowhead indicates putative Alk2-specific bands. Panel B: Realtime PCR analysis of Hfe2 and IdI gene expression in the livers of mask mice. Target mRNA levels were determined relative to Actb mRNA. Asterisk denotes statistical significance $(P<0.05$, $\mathrm{n}=3$ ).

Despite low liver iron levels (Du et al. 2008) and low liver Hjv protein (Fig. 1), liver IdI mRNA levels were increased in mask mice (Fig. 3B). These results are in accordance with data previously reported for other mice with disrupted Tmprss6 gene (Finberg et al. 2010, Nai et al. 2012), confirming the positive effect of Tmprss6 gene disruption on the activity of the Bmp6/Hjv pathway.

\section{Discussion}

During the past decade, the iron regulatory hormone hepcidin has emerged as the key factor which 
controls iron metabolism in mammals (Andrews 2008, Ganz 2011). Consequently, the signaling pathways which regulate hepcidin expression in the hepatocyte represent a subject of intensive research. Hepcidin expression is influenced by several proteins present at the hepatocyte plasma membrane: Hemojuvelin, Tfr2, the Hfe protein and neogenin (Lee et al. 2010). Disruption of any of these proteins leads to decreased hepcidin expression and iron overload. Recently, another hepatocyte membrane protein, the serine protease matriptase-2, has been identified as the only known negative regulator of hepcidin expression. Mutations in the Tmprss6 gene cause inappropriately high expression of hepcidin, resulting in IRIDA (Finberg et al. 2008). The currently accepted model of matriptase- 2 function proposes that matriptase- 2 cleaves hemojuvelin (Silvestri et al. 2008), a GPI-bound protein which serves as a coreceptor for the Bmp6 molecule. However, in vivo evidence for this mode of action of matriptase- 2 is still lacking. Moreover, the possible discrepancy between the in vivo and in vitro effects of Tmprss6-/- mutations has also recently been highlighted by the observation that, in vitro, hepcidin expression is repressed even by those Tmprss6-/mutant constructs which lack protease activity (Guillem et al. 2012). Therefore, it is still of importance to determine the effect of in vivo loss of matriptase-2 proteolytic activity on proteins participating in the regulation of hepcidin expression.

The Bmp6/hemojuvelin signaling pathway, which controls hepcidin expression in response to iron levels, has to a significant extent been elucidated. Iron overload transcriptionally increases the synthesis of Bmp6, which then binds at the extracellular side of the hepatocyte plasma membrane to a set of bone morphogenetic protein receptors. The bone morphogentetic proteins responsible for Bmp6 binding have recently been identified as Alk2 and Alk3 (Steinbicker et al. 2011), both type 1 Bmp receptors. Type $1 \mathrm{Bmp}$ receptors dimerize with type 2 receptors, of which Acvr2a is abundantly expressed in human liver (Xia et al. 2008). Theoretically, all these proteins - Hjv, Alk2, Alk3, the type $2 \mathrm{Bmp}$ receptors, as well as matriptase-2 - should interact at the hepatocyte plasma membrane in order to regulate hepcidin expression. Intriguingly, $\mathrm{Hjv}$ protein level was significantly decreased in mask mice. In this respect, the presented results confirm our data previously obtained in another mouse model with Tmprss6 gene disruption (Krijt et al. 2011). Although the results from both studies do not directly support hemojuvelin cleavage by matriptase-2, they nevertheless apparently confirm a specific interaction between matriptase- 2 and hemojuvelin.

Immunoblotting of liver crude membrane fraction from mask mice has demonstrated a slight decrease in Tfr2 and neogenin protein levels. Tfr2 is known to positively modulate hepcidin expression (Nemeth et al. 2005), but the exact mode of its signal transduction, as well as its possible participation in the Bmp6/hemojuvelin pathway, has not yet been fully elucidated (Chen and Enns 2012, D'Alessio et al. 2012). Tfr2 protein levels are known to respond to plasma iron concentration (Johnson and Enns 2004). Since mask mice are known to display low liver iron levels and plasma iron levels ( $\mathrm{Du}$ et al. 2008), it is plausible that the observed decrease in $\mathrm{Tfr} 2$ protein is caused by iron deficiency, rather than by an interaction between matriptase-2 and Tfr2. This conclusion is in accordance with the recently published finding that Tfr2 is not a substrate for matriptase-2 (Lee et al. 2012).

Neogenin is a ubiquitously expressed protein, which has been demonstrated to interact with hemojuvelin (Zhang et al. 2005). Disruption of the Neol gene in mice has been reported to diminish Bmpdependent signaling and to decrease hepcidin expression, resulting in massive iron overload (Lee et al. 2010). Therefore, matriptase- 2 could theoretically exert its effect on iron metabolism by cleaving membrane neogenin. However, as can be seen in Figure 3, liver membrane neogenin protein content was actually slightly decreased in mask mice, confirming the recently published observation that neogenin is not cleaved by matriptase- 2 (Enns et al. 2012).

Levels of IdI mRNA were increased in mask mice. Id1 is a sensitive indicator of Bmp6-dependent signaling (Kautz et al. 2008), and the observed increase in Id $1 \mathrm{mRNA}$ thus confirms the concept that matriptase-2 blocks Bmp6/hemojuvelin-dependent signaling (Silvestri et al. 2008). How this interference with the Bmp6/Hjv pathway would decrease total $\mathrm{Hjv}$ protein levels is at present unclear. Lack of matriptase-2 proteolytic activity could significantly change the ratio of hemojuvelin to other components of the Bmp6/hemojuvelin pathway, and this imbalance could then affect hemojuvelin protein levels as a compensatory mechanism. It is also possible that matriptase- 2 selectively influences the ratio of the various hemojuvelin forms (Maxson et al. 2009) present at the membrane. As matriptase-2 represents the most recently identified component participating in the complex regulation of hepcidin gene expression, it is 
obvious that more research will be necessary to define its exact function in vivo.

In conclusion, the presented study confirmed decreased expression of hemojuvelin in mice with a mutation in matriptase- 2 gene, while the overall activity of the Bmp6/Hjv pathway, as determined by the IdI gene expression, was increased. The regulation of $\mathrm{Tfr} 2$ protein levels by iron was apparently unaffected. The obtained results confirm the inhibitory effect of matriptase- 2 on the Bmp6/hemojuvelin dependent signaling pathway, and suggest a complex relationship between matriptase-2 expression and hemojuvelin protein levels.

\section{Conflict of Interest}

There is no conflict of interest.

\section{Acknowledgements}

Supported by grants PRVOUKP24/LF1/3, SVV-2012264507 and UNCE 204021 from Charles University. The supply of mask mice samples by Dr. Pauline Lee, The Scripps Research Institute, La Jolla, CA, USA, as well as the donation of $\mathrm{Hjv}$-/- mice by Prof. Silvia Arber, University of Basel and Friedrich Miescher Institute, Basel, Switzerland, is gratefully acknowledged.

\section{References}

ANDREWS NC: Forging a field: the golden age of iron biology. Blood 112: 219-230, 2008.

ANDRIOPOULOS B JR, CORRADINI E, XIA Y, FAASSE SA, CHEN S, GRGUREVIC L, KNUTSON MD, PIETRANGELO A, VUKICEVIC S, LIN HY, BABITT JL: BMP6 is a key endogenous regulator of hepcidin expression and iron metabolism. Nat Genet 41: 482-487, 2009.

BABITT JL, HUANG FW, WRIGHTING DM, XIA Y, SIDIS Y, SAMAD TA, CAMPAGNA JA, CHUNG RT, SCHNEYER AL, WOOLF CJ, ANDREWS NC, LIN HY: Bone morphogenetic protein signaling by hemojuvelin regulates hepcidin expression. Nat Genet 38: 531-539, 2006.

CHEN J, ENNS CA: Hereditary hemochromatosis and transferrin receptor 2. Biochim Biophys Acta 1820: 256-263, 2012.

D'ALESSIO F, HENTZE MW, MUCKENTHALER MU: The hemochromatosis proteins HFE, TfR2, and HJV form a membrane-associated protein complex for hepcidin regulation. J Hepatol 57: 1052-1060, 2012.

DU X, SHE E, GELBART T, TRUKSA J, LEE P, XIA Y, KHOVANANTH K, MUDD S, MANN N, MORESCO EM, BEUTLER E, BEUTLER B: The serine protease TMPRSS6 is required to sense iron deficiency. Science 320: 1088-1092, 2008.

ENNS CA, AHMED R, ZHANG AS: Neogenin interacts with matriptase-2 to facilitate hemojuvelin cleavage. $J$ Biol Chem 287: 35104-35117, 2012.

FINBERG KE, HEENEY MM, CAMPAGNA DR, AYDINOK Y, PEARSON HA, HARTMAN KR, MAYO MM, SAMUEL SM, STROUSE JJ, MARKIANOS K, ANDREWS NC, FLEMING MD: Mutations in TMPRSS6 cause iron-refractory iron deficiency anemia (IRIDA). Nat Genet 40: 569-571, 2008.

FINBERG KE, WHITTLESEY RL, FLEMING MD, ANDREWS NC: Down-regulation of Bmp/Smad signaling by Tmprss6 is required for maintenance of systemic iron homeostasis. Blood 115: 3817-3826, 2010.

FLEMING RE, MIGAS MC, HOLDEN CC, WAHEED A, BRITTON RS, TOMATSU S, BACON BR, SLY WS: Transferrin receptor 2: continued expression in mouse liver in the face of iron overload and in hereditary hemochromatosis. Proc Natl Acad Sci USA 97: 2214-2219, 2000.

FOLGUERAS AR, DE LARA FM, PENDÁS AM, GARABAYA C, RODRÍGUEZ F, ASTUDILLO A, BERNAL T, CABANILLAS R, LÓPEZ-OTÍN C, VELASCO G: Membrane-bound serine protease matriptase-2 (Tmprss6) is an essential regulator of iron homeostasis. Blood 112: 2539-2545, 2008.

GANZ T: Hepcidin and iron regulation, 10 years later. Blood 117: 4425-4433, 2011.

GUILLEM F, KANNENGIESSER C, OUDIN C, LENOIR A, MATAK P, DONADIEU J, ISIDOR B, MÉCHINAUD F, AGUILAR-MARTINEZ P, BEAUMONT C, VAULONT S, GRANDCHAMP B, NICOLAS G: Inactive matriptase-2 mutants found in IRIDA patients still repress hepcidin in a transfection assay despite having lost their serine protease activity. Hum Mutat 33: 1388-1396, 2012.

JOHNSON MB, ENNS CA: Diferric transferrin regulates transferrin receptor 2 protein stability. Blood 104: 4287-4293, 2004. 
KAUTZ L, MEYNARD D, MONNIER A, DARNAUD V, BOUVET R, WANG RH, DENG C, VAULONT S, MOSSER J, COPPIN H, ROTH MP: Iron regulates phosphorylation of Smad1/5/8 and gene expression of Bmp6, Smad7, Id1, and Atoh8 in the mouse liver. Blood 112: 1503-1509, 2008.

KRIJT J, FUJIKURA Y, RAMSAY AJ, VELASCO G, NEČAS E: Liver hemojuvelin protein levels in mice deficient in matriptase-2 (Tmprss6). Blood Cells Mol Dis 47: 133-137, 2011.

LEE DH, ZHOU LJ, ZHOU Z, XIE JX, JUNG JU, LIU Y, XI CX, MEI L, XIONG WC: Neogenin inhibits HJV secretion and regulates BMP-induced hepcidin expression and iron homeostasis. Blood 115: 3136-3145, 2010.

LEE P, HSU MH, WELSER-ALVES J, PENG H: Severe microcytic anemia but increased erythropoiesis in mice lacking Hfe or Tfr2 and Tmprss6. Blood Cells Mol Dis 48: 173-178, 2012.

MAXSON JE, ENNS CA, ZHANG AS: Processing of hemojuvelin requires retrograde trafficking to the Golgi in HepG2 cells. Blood 113: 1786-1793, 2009.

MEYNARD D, KAUTZ L, DARNAUD V, CANONNE-HERGAUX F, COPPIN H, ROTH MP: Lack of the bone morphogenetic protein BMP6 induces massive iron overload. Nat Genet 41: 478-481 2009.

NAI A, PAGANI A, MANDELLI G, LIDONNICI MR, SILVESTRI L, FERRARI G, CAMASCHELLA C: Deletion of TMPRSS6 attenuates the phenotype in a mouse model of $\beta$-thalassemia. Blood 119: 5021-5029, 2012.

NEMETH E, ROETTO A, GAROZZO G, GANZ T, CAMASCHELlA C: Hepcidin is decreased in TFR2 hemochromatosis. Blood 105: 1803-1806, 2005.

SILVESTRI L, PAGANI A, NAI A, DE DOMENICO I, KAPLAN J, CAMASCHELlA C: The serine protease matriptase-2 (TMPRSS6) inhibits hepcidin activation by cleaving membrane hemojuvelin. Cell Metab 8: 502$511,2008$.

STEINBICKER AU, BARTNIKAS TB, LOHMEYER LK, LEYTON P, MAYEUR C, KAO SM, PAPPAS AE, PETERSON RT, BLOCH DB, YU PB, FLEMING MD, BLOCH KD: Perturbation of hepcidin expression by BMP type I receptor deletion induces iron overload in mice. Blood 118: 4224-4230, 2011.

XIA Y, BABITT JL, SIDIS Y, CHUNG RT, LIN HY: Hemojuvelin regulates hepcidin expression via a selective subset of BMP ligands and receptors independently of neogenin. Blood 111: 5195-5204, 2008.

ZHANG AS, WEST AP JR, WYMAN AE, BJORKMAN PJ, ENNS CA: Interaction of hemojuvelin with neogenin results in iron accumulation in human embryonic kidney 293 cells. J Biol Chem 280: 33885-33894, 2005. 